\section{Discussion}

Urinary tract calculi are common and there is some evidence that the incidence of symptomatic stones is increasing. ${ }^{8}$ In a random sample of 3398 patients in an urban population in Scotland the prevalence of upper urinary tract calculi was $3.5 \% .{ }^{9}$ It has been estimated that $12 \%$ of males will suffer from at least one episode of ureteric colic secondary to stones during their lifetime ${ }^{8}$ and half these patients will have at least one recurrence within five years. " The severe pain associated with ureteric colic necessitates the use of potent analgesics such as opiates or their derivatives. Confirmed narcotic addicts exploit this need by simulating the signs and symptoms of ureteric colic in an effort to gain access to opiates. Furthermore, the repeated use of these drugs may lead to physical dependence in non-addicts. There is therefore a need for potent, non-dependent analgesic agents.

The ideal analgesic in ureteric colic should provide excellent pain relief, a long duration of action, no side effects, and some smooth-muscle relaxation. In this study buprenorphine provided significantly improved pain relief, a longer duration of action, and better sedation than pethidine. Complications associated with both drugs were few: nausea and vomiting have been attributed to buprenorphine in other studies but occurred equally in both groups of patients in this study.

That fewer patients receiving buprenorphine required further analgesia may suggest that buprenorphine possesses a pharmacological action other than that of pure analgesia. It produces mild smooth-muscle contraction and recent studies in animals suggest that this may promote the passage of small calculi.. ${ }^{11}$ Despite five years of clinical use it shows little or no potential for addiction, and our results suggest that it may be a realistic alternative to the traditional opiates in patients with ureteric colic. It must be remembered, however, that clinicians can assess the addiction potential of any drug only after several years of wide experience.

\section{References}

${ }^{1}$ Scott R, Freeland R, Mowat W, et al. The prevalence of calcified upper urinary tract stone disease in a random population. Br $\mathcal{F}$ Urol 1977;49: 589-95.

2 Anonymous. Recurrent renal calculi. $B r$ Med f 1981 ;282:5.

${ }^{3}$ Walsh A. Renal colic. Br f Hosp Med 1978;19:224-6.

Lewis JW. Ring C-bridged derivatives of thebaine and oripavine. $A d v$ Biochem Psychopharmacol 1974;8:123-36.

5 Downing JW, Leary WP, White ES. Buprenorphine: a new potent long acting synthetic analgesic. Comparison with morphine. $\mathrm{Br} \mathcal{F}$ Anaesth $1977 ; 49: 251-4$

${ }^{6}$ Jasinski DR, Pevnick JS, Griffith JD. Human pharmacology and abuse potential of the analgesic buprenorphine: a potential agent for treating narcotic addiction. Arch Gen Psychiatry 1978;35:501-16.

7 Huskisson EC. Measurement of pain. Lancet 1974;ii:1127.

${ }^{8}$ Sierakowski R, Finlayson B, Landes RR, Finlayson CD, Sierakowski N. The frequency of urolithiasis in hospital discharge diagnosis in the United States. Invest Urol 1978;15:438-41.

${ }^{9}$ Scott R, Freeland R, Mowat W. The prevalence of renal stones in a random population and volunteer population. In: Brockis JS, Finlayson B, eds. Urinary calculus. Littleton, Mass, USA: PSG, 1981.

${ }^{10}$ Ljunghall S, Backman V, Danielson BG, et al. Long term treatment with Bendrofluromethiazide for prevention of renal stones. In: Smith $\mathrm{LH}$ Robertson WG, Finlayson B, eds. Urolithiasis: clinical and basic research. New York and London: Plenum Press, 1981.

11 Watson GS, Edmond P. Analgesics and ureteral function. In: Harcus AW, Smith R, Whittle B, eds. Pain. Edinburgh: Churchill Livingstone, 1977 : 27-33.

(Accepted 16 April 1982)

\title{
Hypnotherapy for incontinence caused by the unstable detrusor
}

\author{
R M FREEMAN, K BAXBY
}

\begin{abstract}
Fifty incontinent women with proved detrusor instability completed 12 sessions of hypnosis (symptom removal by direct suggestion and "ego strengthening") over one month. This was continued at home with a prerecorded cassette, and all patients were followed up for at least six months. At the end of the 12 sessions 29 patients were entirely symptom free, 14 improved, and seven unchanged. Three months later cystometry in 44 of the patients showed conversion of the cystometrogram to stability in 22 and a significant improvement in a further 16; only six showed no objective improvement. Seven patients relapsed (three after bereavement). Further treatment was given and five out of six patients were rendered symptom free again. Patients with detrusor instability were not found to have a noticeably increased susceptibility to hypnosis.
\end{abstract}

It is concluded that psychological factors are very important in "idiopathic" detrusor instability and that

Department of Urology, Royal Infirmary, Dundee DD1 9ND

R M FREEMAN, $M B$, CHB, senior house officer (now registrar, departments of obstetrics and gynaecology, St Helier Hospital, Carshalton, Surrey, and St George's Hospital, London SW 17)

$\mathrm{K}$ BAXBY, BSC, FRCS, consultant urological surgeon hypnotherapy is effective for incontinence due to this disorder.

\section{Int roduction}

Urinary incontinence is one of the most socially incapacitating problems for many women today. It is now known to be more prevalent than was previously thought. ${ }^{1}$ A common cause of incontinence is an unstable detrusor (detrusor instability). In this condition a person lacks the ability to inhibit detrusor contractions during bladder filling. Detrusor instability usually produces symptoms of frequency, urgency, and urge incontinence. The exact prevalence of the condition is uncertain but it is probably present in about half of all women presenting with urinary incontinence.

The view that uninhibited detrusor contractions cause incontinence is not new, ${ }^{34}$ but with the advent of urodynamic investigations the diagnosis has become easier to confirm and detrusor instability has become a clinical entity in its own right. The aetiology of the condition remains obscure. Apart from outflow obstruction (more common in men) and neurological disease (for example, multiple sclerosis), in the vast majority of cases no cause can be found. It is therefore not surprising that treatment often fails. Apart from bladder retraining (see below) there is nothing which will reliably convert instability to stability. One hypothesis is that the condition is psycho- 
somatic. ${ }^{5}$ This is not new, however, since the effect of the psyche on bladder function has been known for a long time. ${ }^{6} 7$

If psychological factors do play a part in detrusor instability then applying psychological influences such as hypnosis should have some effect. Psychological influences in other treatments for detrusor instability such as bladder retraining ${ }^{8} 9$ and biofeedback ${ }^{10}$ have shown encouraging results. Hypnosis has been misunderstood in the past, however, and even now is not taken seriously by some sections of the profession. Research over the past 20 years has helped to remove many misconceptions, and hypnosis is now used extensively for pain, psychosomatic disorders, and nocturnal enuresis in children.

There is no universally accepted definition of hypnosis but it is probably a state of consciousness which has certain characteristics, outstanding of which is susceptibility to suggestion. Hypnosis can influence the function of the central and autonomic nervous systems and may be used in three ways: by relaxationfor example, self-hypnosis; symptom removal by direct suggestion; and hypnoanalysis. ${ }^{11}$

The aims of our study were, firstly, to see whether hypnosis was a useful treatment for incontinence of urine due to detrusor instability; secondly, to test the hypothesis that psychological factors are important in the aetiology of detrusor instability (by removing symptoms via hypnosis); and, thirdly, to see if women with detrusor instability were more than usually suggestible (as has been proposed ${ }^{12}$ ) and so more amenable to hypnotherapy.

\section{Patients and methods}

Sixty-three incontinent women aged 17-74 years (mean $44 \cdot 0 \pm 15 \cdot 6$ years) were admitted to the study. Criteria for admission were: urodynamically proved detrusor instability; no evidence of genuine stress incontinence; no evidence of outflow obstruction (obstruction being indicated by a flow rate of less than $15 \mathrm{ml} / \mathrm{s}$ or a voiding pressure of greater than $70 \mathrm{~cm} \mathrm{H}_{2} \mathrm{O}$ or both); normal appearances on cystoscopy; normal neurological findings; and no drugs being taken which might affect the detrusor.

All patients were investigated urodynamically-that is by filling and voiding cystometry with synchronous videocystourethrography. Vesical, rectal, and (subtracted) detrusor pressures were measured during filling and voiding while the bladder and urethra were observed by $x$-ray screening. Provocative cystometry included rapid filling at $100 \mathrm{ml} / \mathrm{min}$ as well as coughing, change of posture from supine to erect, and turning on water taps. Detrusor instability was diagnosed when contractions exceeding $15 \mathrm{~cm} \mathrm{H}_{2} \mathrm{O}$ were observed which the patient was unable to inhibit. After filling, a voiding pressure and flow rate were obtained at the same time as cystourethrography to exclude outflow obstruction. Figure 1 shows a normal cystometrogram. Figure 2 shows a pattern of detrusor instability commonly known as "systolic" (this term is not, however, recommended by International Continence Society), and fig 3 shows a form of detrusor instability commonly known as low compliance (steep cystometrogram).

The question of using a randomised control group of patients with detrusor instability was carefully considered, and it was thought unethical to ask incontinent patients to serve as untreated controls. Furthermore, the patients had been referred by general practitioners and consultants for treatment. We therefore decided that after cystoscopy, neurological examination, urodynamic studies, and an explanation of the cause of the symptoms one month would be allowed to elapse in order to assess any effect of these measures on the symptoms. During this period each patient served as her own control. All patients were followed up for at least six months after treatment and results during that time documented.

Treatment consisted of 12 sessions of hypnosis-that is, symptom removal by direct suggestion and ego-strengthening suggestions over one month. This was continued at home with a prerecorded cassette. Hypnotic induction employed eye-fixation techniques, and deepening was by appropriate suggestion. Depth of hypnotic state was assessed using the Stanford Hypnotic Clinical Scale. ${ }^{13}$ So that progress could be assessed objectively, voiding charts indicating frequency of micturition and incontinence were kept by the patients during treatment. Three months after the end of the initial 12 sessions patients were asked to attend for repeat cystometry. Follow-up of all patients who completed treatment ranged from six to 14 months.
Urodynamic variables before and after treatment were tested for significant differences using Student's paired $t$ test. Hypnotic susceptibility scores for study patients and published norms were compared using the $\chi^{2}$ test.

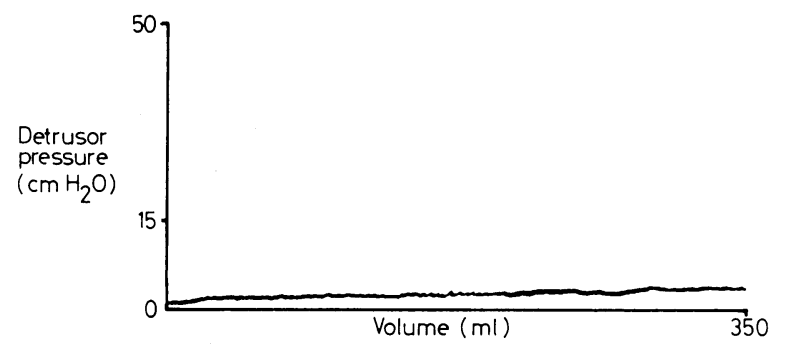

FIG I-Appearance of stable cystometrogram.

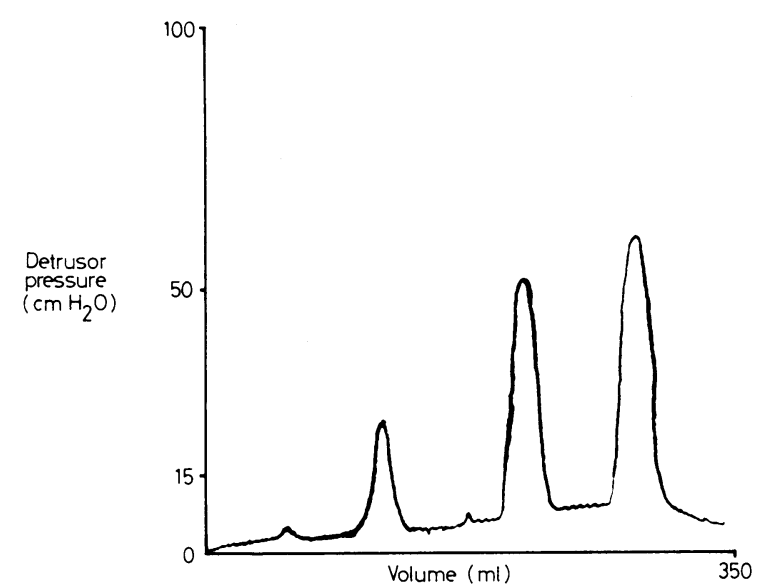

FIG 2-Unstable cystometrogram in detrusor instability showing "systolic" pattern.

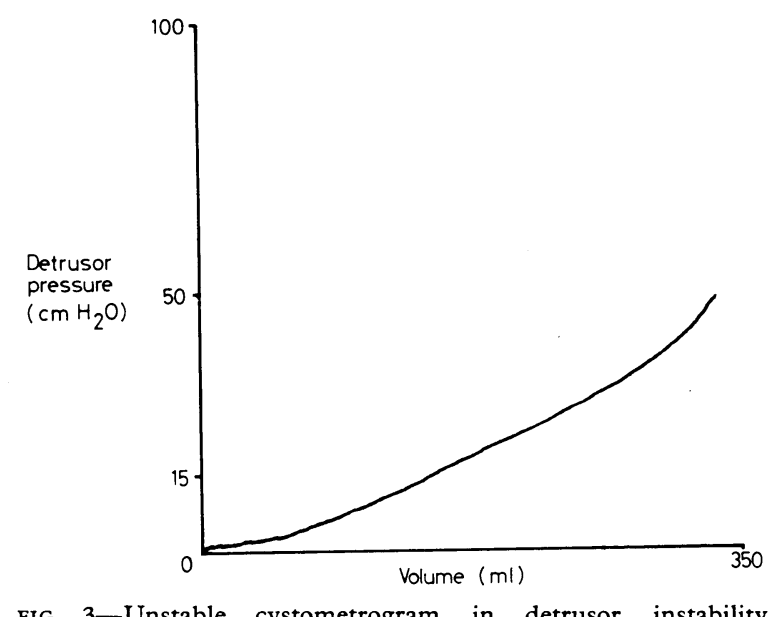

FIG 3-Unstable cystometrogram in detrusor instability showing low-compliance pattern.

\section{Results}

During the one-month control period one patient was rendered symptom free and declined further treatment. Eight patients were improved symptomatically but requested treatment. The other 54 patients had no change in symptoms during the control period. Two patients who had no change in symptoms refused treatment.

In the original study population $(n=63)$ pretreatment mean maximal cystometric capacity was $410 \cdot 0 \pm 13 \cdot 3 \mathrm{ml}$ (range $120-650 \mathrm{ml}$ ) and height of unstable contraction $43 \cdot 6 \pm 22 \cdot 1 \mathrm{~cm} \mathrm{H}_{2} \mathrm{O}$ (range $15-100 \mathrm{~cm} \mathrm{H}_{2} \mathrm{O}$ ). Mean volume to first unstable contraction was 
$318.0 \pm 14.4 \mathrm{ml}$ (range $50-650 \mathrm{ml}$ ). Fifty-two patients had "systolic" cystometrograms, and seven patients showed the low-compliance pattern. Four patients had a combination of the two types of cystometrogram, low compliance (fig 3) being the major component in three of them.

Fifty patients completed the 12 sessions of treatment (10 defaulted). At the end of the 12 sessions 29 patients were entirely symptom free, 14 considerably improved-that is to a degree which improved their life style; and seven patients showed no change in symptoms.

Six patients refused repeat cystometry after treatment. Of the remaining 44 patients, 22 had their instability converted to stability as judged by the cystometrogram (table I). In six the post-treatment

TABLE I-Results of cystometry after treatment in 44 patients (all had unstable cystometrograms before treatment)

\begin{tabular}{|c|c|c|c|}
\hline \multirow{2}{*}{ Cystometrogram } & \multicolumn{3}{|c|}{ Symptoms after treatment } \\
\hline & Symptom free & Improved & No change \\
\hline $\begin{array}{l}\text { Stable } \\
\text { Unstable (low compliance) } \\
\text { Unstable (systolic) } \ldots \\
\text { No change . . . } \\
\text { Mean maximal cystometric } \\
\text { capacity } \rightarrow \mathrm{SD}(\mathrm{ml}) \text { (range) }\end{array}$ & $\begin{array}{c}17 \\
4 \\
5 \\
1 \\
499 \pm 102 \\
(300-730)\end{array}$ & $\begin{array}{c}4 \\
1 \\
4 \\
4 \\
428 \div 123 \\
(250-600)\end{array}$ & $\begin{array}{c}1 \\
1 \\
1 \\
1 \\
500 \pm 178 \\
(250-650)\end{array}$ \\
\hline
\end{tabular}

cystometrogram showed low compliance compared with the previously systolic pattern. In these patients towards the end of filling in the erect position a steep rise in pressure over $15 \mathrm{~cm} \mathrm{H}_{2} \mathrm{O}$ was noted and they were therefore included in the unstable cystometrogram group. Ten patients had improved unstable cystometrograms-that is, bladder capacity and volume to first unstable contraction were increased and height of the unstable contraction was reduced. Six patients showed no objective change.

In all 44 patients who had urodynamic studies performed after treatment the mean maximal cystometric capacity was significantly increased from the pretreatment value (before treatment $378 \pm 126 \mathrm{ml}$, after treatment $487+117 \mathrm{ml}$; mean difference $92.3 \pm 112.2 \mathrm{ml}$; $p<0.001)$. In the patients in whom the cystometrogram remained unstable $(n=16)$ the height of the unstable contraction was significantly reduced (before treatment $57.5+23.3 \mathrm{~cm} \mathrm{H}_{2} \mathrm{O}$, after treatment $39.0-13.2 \mathrm{~cm} \mathrm{H}_{2} \mathrm{O}$; mean difference $18.5 \pm 18.9 \mathrm{~cm} \mathrm{H}_{2} \mathrm{O} ; 0.01>$ $\mathrm{p}>0.001)$ and the volume to first contraction significantly increased (before treatment $245+159 \mathrm{ml}$, after treatment $337+123 \mathrm{ml}$; mean difference $92.2 \pm 126 \mathrm{ml} ; 0.02>\mathrm{p}>0.01$ ) compared with the pretreatment values.

Seven patients (five of whom had been symptom-free) relapsed: three at one year and one each at 10, eight, seven, and two months. Three relapses occurred after the death of a close relative. Further treatment was given to six patients, and five were rendered symptom free again. Table II shows the hypnotic susceptibility scores in the study population compared with the published norms. The differences were not significant $\left(\chi^{2}=0.916 ; \mathrm{df}=2\right)$.

TABLE II-Hypnotic susceptibility scores in study population compared with norms

\begin{tabular}{|c|c|c|c|}
\hline & \multicolumn{3}{|c|}{ Susceptibility score } \\
\hline & High & Medium & Low \\
\hline $\begin{array}{l}\text { Study group (detrusor instability) } \\
\text { Published norms } \ldots\end{array}$ & $\begin{array}{l}45 \% \\
37 \%\end{array}$ & $\begin{array}{l}35 \% \\
37 \%\end{array}$ & $\begin{array}{l}20 \% \\
26 \%\end{array}$ \\
\hline
\end{tabular}

\section{Discussion}

Hypnosis has been used in only a few cases of detrusor instability, ${ }^{14}$ yet it is used in many psychosomatic disorders ${ }^{15}$ as well as for childhood nocturnal enuresis. ${ }^{16}$ Bladder retraining and biofeedback aim at improving bladder control at the conscious level; hypnosis aims at doing this at an unconscious level. Hypnosis is non-invasive, inexpensive of time and staff, and does not require hospital admission. Motivation and intelligence of patients, while helpful, are not essential. The likelihood of success from hypnosis is enhanced if there is a good doctor-patient relationship. In our study, therefore, the interview, urodynamic studies, and treatment were all carried out by the same person (RF).

There has been concern that simply removing symptoms by direct suggestion under hypnosis may lead to relapse once treatment is stopped because the underlying psychological cause has not been established. We did not attempt to find underlying causes by using age regression or hypnoanalysis. Stirring up unpleasant memories may upset the patient, and there is no conclusive evidence that establishing an underlying cause will improve the condition any better than by symptom removal alone. Only seven patients relapsed during follow-up, and three relapses were clearly associated with bereavement. The other 43 symptom-free or improved patients showed no evidence of relapse during follow-up varying from six to 14 months.

It has been claimed that after symptom removal more serious substitution symptoms may emerge, such as suicidal tendencies or personality changes. These have been observed mainly when removing symptoms from patients with hysterical neuroses. ${ }^{17}$ Detrusor instability by definition is not a hysterical condition because in all hysterical neuroses the functional system is normal by objective tests. In detrusor instability results of objective cystometry are abnormal. It is therefore unlikely that serious substitution symptoms may emerge, and none were observed in this series.

A further problem which may arise after hypnosis is dependence by the patient on the physician. If treatment is stopped abruptly relapse may occur. In an attempt to prevent this, patients continued the treatment at home using a prerecorded cassette. Gradually treatment at the outpatient clinic was tailed off by increasing the intervals between visits.

After 12 sessions of treatment only seven patients showed no subjective improvement. Twenty-nine were entirely symptom free, and 14 were improved to an extent which helped their life style. Urodynamic testing of 44 patients showed that 22 of them had entirely stable detrusors after treatment; only six showed no improvement. The mean maximal cystometric capacity after treatment was significantly increased compared with the pretreatment value. All variables were significantly improved in the 16 patients whose cystometrograms remained unstable, indicating an improvement in detrusor function.

It may be argued that the absence of a randomised control group reduced the strength of our findings. We believed, however, that it would be totally unethical to ask a control group of patients to attend an outpatient clinic 12 times for no treatment, to have urodynamic studies repeated at three months, and to be followed up for at least six months. Our patients had longstanding symptoms (mean 7 years; range 1-40 years) and had failed to improve with other forms of treatment (drugs, etc) before referral. Each patient served as her own control before treatment and was followed up for at least six months after treatment.

The effect of hypnosis on detrusor instability (especially our results) lends support to the hypothesis that psychological factors are important in the causation of "idiopathic" detrusor instability. Further evidence for this is the well-known placebo response rate of about $25 \%$ from any treatment for this condition. This does not mean that detrusor instability is purely psychogenic in origin; it is probably a true psychosomatic disorder.

As to the hypothesis that patients with detrusor instability may be more than usually suggestible and therefore more hypnotisable the hypnotic susceptibility scores were not significantly different from the norms. Hence there was no apparent increased susceptibility to hypnosis in patients with detrusor instability.

Our results show that psychological factors are extremely important in the causation of idiopathic detrusor instability. Hypnosis is a valuable method of treatment for incapacitating urinary incontinence caused by detrusor instability. It may be carried out by any doctor who is prepared to undergo minimal 
training, so that assessment and treatment may be performed by the same clinician.

(Methods, definitions, and units conform to the standards proposed by the International Continence Society, except where specifically noted.)

\section{References}

1 Thomas TM, Plymat KR, Blannin J, Meade TW. Prevalence of urinary incontinence. Br Med f 1980;281:1243-5.

${ }^{2}$ Farrar DJ, Whiteside CG, Osborne JL, Turner-Warwick RT. A urodynamic analysis of micturition symptoms in the female. Surg Gynecol Obstet 1975;141:875-81.

${ }^{3}$ Dudley EC. The expansion of gynecology, and a suggestion for the surgical treatment of incontinence of urine in women. Transactions of the American Gynecological Society 1905;30:3-14.

${ }^{4}$ Hodgkinson CP, Ayers MA, Drukker BH. Dyssynergic detrusor dysfunction in the apparently normal female. Am $\mathcal{f}$ Obstet Gynecol $1963 ; 87: 717-30$.

${ }^{5}$ Frewen WK. Urgency incontinence. $\mathcal{F}$ Obstet Gynaecol Br Commonw $1972 ; 79: 77-9$.

6 Janet J (1890). Les troubles psychopathiques de la miction. Essai de psychophysiologie normale et pathologique. In: Smith DR, Auerback A.
Functional diseases. Encyclopedia of urology. Vol 12. Berlin: SpringerVerlag, $1960: 1-20$

Freud S (1905). Three essays on the theory of sexuality. In: The standard edition of the complete psychological works of Sigmund Freud. Vol 7. London: Hogarth Press, 1953.

${ }^{8}$ Frewen WK. An objective assessment of the unstable bladder of psychosomatic origin. $\mathrm{Br} \mathcal{F}$ Urol $1978 ; \mathbf{5 0}: 246-9$.

${ }^{9}$ Jarvis GJ, Millar DR. Controlled trial of bladder drill for detrusor instability. Br Med f 1980;281:1322-3.

10 Cardozo LD, Abrams PD, Stanton SL, Feneley RCL. Idiopathic detrusor instability treated by biofeedback. Br $\mathcal{F}$ Urol 1978;50:521-3.

"Frankel $\mathrm{FH}$. Hypnosis as a treatment method in psychosomatic medicine. Int F Psychiatry Med 1975;6:75-85.

12. Stone CB, Judd GE. Psychogenic aspects of urinary incontinence in women. Clin Obstet Gynecol 1978;21:807-15.

${ }^{13}$ Morgan AH, Hilgard JR. Stanford Hypnotic Clinical Scale. In: Hilgard ER, Hilgard JR, eds. Hypnosis in the relief of pain. Los Altos, California: Kauffmann, 1975:appendix A

${ }^{14}$ Godec CJ. Inhibition of hyperreflexic bladder during hypnosis: a case report. Am f Clin Hypn $1979 ; 22: 170-2$.

${ }^{15}$ Maher-Loughnan GP. Clinical applications of hypnosis in medicine. Br 7 Hosp Med 1980a ;23:447-55.

${ }^{16}$ Olness $\mathrm{K}$. The use of self-hypnosis in the treatment of childhood nocturnal enuresis. Clin Pediatr 1975;14:273-5.

17 Hartland J. The hypnotic treatment of psychosomatic symptoms and psychological illness. In: Medical and dental hypnosis and its clinical applications. London: Baillière Tindall, 1971 :ch 22.

(Accepted 23 April 1982)

\section{SHORT REPORTS}

\section{Pneumatosis cystoides coli in chronic respiratory failure}

Pneumatosis cystoides of the colon is characterised by multiple gasfilled cysts in the colonic submucosa that cause chronic diarrhoea and colicky pain. Treatment with metronidazole has been suggested ${ }^{1}$ but the treatment of choice is intermittent hyperoxygenation. ${ }^{2}$ In patients with concomitant chronic hypoxic lung disease hyperoxygenation will often necessitate mechanical ventilation due to the risk of carbon dioxide intoxication. We suggest that this problem may be surmounted by combined treatment with hyperoxygenation and a respiratory stimulant.

\section{Case report}

A 67-year-old man with chronic hypoxic obstructive lung disease was admitted to hospital for diarrhoea, loss of weight, and abdominal pain necessitating daily administration of opiates. Pneumatosis cystoides of the large bowel was diagnosed by rectosigmoidoscopy, rectal biopsy, and barium enema. Conventional treatment with oxygen through a nasal catheter proved

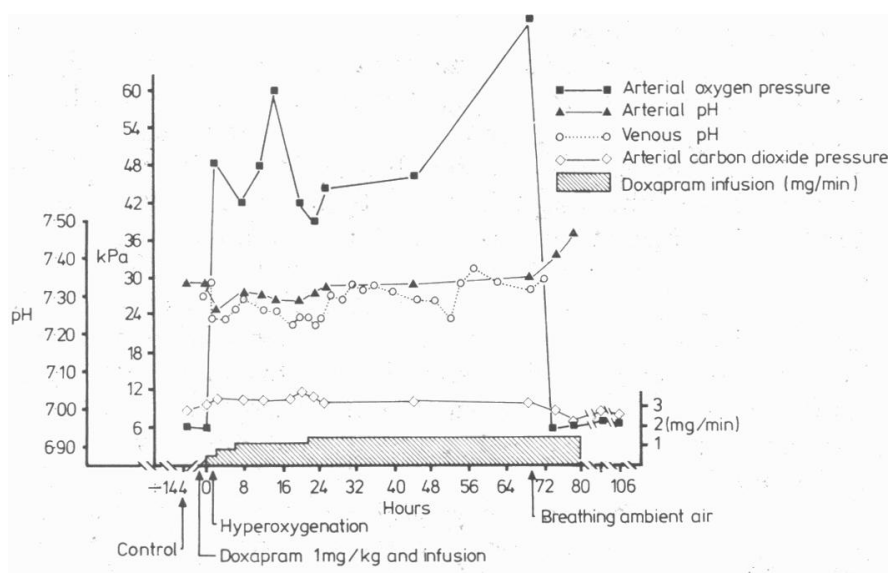

Respiratory measurements during hyperoxygenation.

Conversion: SI to traditional units-Arterial oxygen pressure and arterial carbon dioxide pressure: $1 \mathrm{kPa} \approx 7.5 \mathrm{~mm} \mathrm{Hg}$. impossible as even $11 /$ min caused severe respiratory depression with an increase in arterial carbon dioxide pressure from $8.6 \mathrm{kPa}$ to $11.2 \mathrm{kPa}(65$ $\mathrm{mm} \mathrm{Hg}$ to $84 \mathrm{~mm} \mathrm{Hg}$ ). Metronidazole $2400 \mathrm{mg}$ daily for nine days produced no effect.

To facilitate hyperoxygenation the patient was given an infusion of doxapram hydrochloride preceded by an intravenous bolus of $1 \mathrm{mg} / \mathrm{kg}$ (figure). His tidal volume immediately increased and he felt dyspnoeic and hyperinflated. There was no immediate change in respiratory rate, blood pressure, or pulse rate, but during treatment the blood pressure fell from 140/80 $\mathrm{mm} \mathrm{Hg}$ to $120 / 70 \mathrm{~mm} \mathrm{Hg}$. Periodic continuous positive airway pressure ${ }^{3}$ of $5 \mathrm{~cm}$ water was given for five minutes every two hours to prevent atelectasis during hyperoxygenation, and the continuous positive airway pressure also diminished the dyspnoea.

After 30 minutes of doxapram infusion hyperoxygenation was started at $15 \mathrm{l} / \mathrm{min}$ through a nasal catheter. Treatment was monitored by gas analysis of central venous blood samples. Arterial puncture analysis was restricted to determining arterial oxygen tension (figure). After 72 hours of continuous hyperoxygenation and doxapram infusion bowel movements were normal and the abdominal pain had disappeared. Opiates were no longer needed. Proctoscopy and barium enema showed normal colonic mucosa. Oxygen was withdrawn and doxapram gradually discontinued. No adverse effects were observed, and two months later the patient had not had a relapse or needed opiates.

\section{Comment}

Our patient suffered severe respiratory insufficiency, probably aggravated by regular intake of opiates for painful pneumatosis cystoides of the colon. Metronidazole had no effect, and we therefore had to decide between hyperoxygenation under cover of a respiratory stimulant or mechanical ventilation. Doxapram hydrochloride is a valuable respiratory stimulant ${ }^{4}$ in chronic respiratory insufficiency and has a commendable therapeutic margin. ${ }^{5}$ In our patient doxapram prevented respiratory depression due to hyperoxygenation and no adverse reactions were seen, probably because of the low dose used. 45

Hyperinflation increases the effort of breathing, which may explain the lack of efficacy of doxapram in some patients during short periods of breathing pure oxygen. ${ }^{4}$ Possibly the hyperinflation in our patient was reduced by the periodic use of continuous positive airway pressure ${ }^{3}$ which presumably reduces airway resistance in emphysematous lungs, thereby reducing the dyspnoea. The pneumatosious cysts regressed in our patient after only 72 hours' treatment, which was faster than earlier reported. This may have been due to individual differences or to the high arterial oxygen tension maintained with our method.

Although the evidence is uncontrolled, combined respiratory stimulation with doxapram and high oxygen supply administered 